University of Nebraska - Lincoln

DigitalCommons@University of Nebraska - Lincoln

Roman L. Hruska U.S. Meat Animal Research

U.S. Department of Agriculture: Agricultural Center

Research Service, Lincoln, Nebraska

2003

\title{
Accuracy of predicting weight and percentage of beef carcass retail product using ultrasound and live animal measures
}

\author{
S. P. Greiner \\ lowa State University, sgreiner@vt.edu \\ G. H. Rouse \\ lowa State University \\ D. E. Wilson \\ lowa State University \\ L. V. Cundiff \\ U.S. Meat Animal Research Center, Larry.Cundiff@ars.usda.gov
}

T. L. Wheeler

Roman L. Hruska U.S. Meat Animal Research Center, tommy.wheeler@ars.usda.gov

Follow this and additional works at: https://digitalcommons.unl.edu/hruskareports

Greiner, S. P.; Rouse, G. H.; Wilson, D. E.; Cundiff, L. V.; and Wheeler, T. L., "Accuracy of predicting weight and percentage of beef carcass retail product using ultrasound and live animal measures" (2003). Roman L. Hruska U.S. Meat Animal Research Center. 363.

https://digitalcommons.unl.edu/hruskareports/363

This Article is brought to you for free and open access by the U.S. Department of Agriculture: Agricultural Research Service, Lincoln, Nebraska at DigitalCommons@University of Nebraska - Lincoln. It has been accepted for inclusion in Roman L. Hruska U.S. Meat Animal Research Center by an authorized administrator of DigitalCommons@University of Nebraska - Lincoln. 


\title{
Accuracy of predicting weight and percentage of beef carcass retail product using ultrasound and live animal measures
}

\author{
S. P. Greiner*1, G. H. Rouse*, D. E. Wilson*, L. V. Cundiff $\dagger$, and T. L. Wheeler $\dagger$ \\ *Department of Animal Science, Iowa State University, Ames 50011 and †Roman L. Hruska \\ U.S. Meat Animal Research Center, USDA, ARS, Clay Center, NE 68933
}

\begin{abstract}
Five hundred thirty-four steers were evaluated over a 2-yr period to develop and validate prediction equations for estimating carcass composition from live animal ultrasound measurements and to compare these equations with those developed from carcass measurements. Within $5 \mathrm{~d}$ before slaughter, steers were ultrasonically measured for 12th-rib fat thickness (UFAT), longissimus area (ULMA), rump fat thickness (URPFAT), and body wall thickness (UBDWALL). Carcasses were fabricated to determine weight (KGRPRD) and percentage (PRPRD) of boneless, totally trimmed retail product. Data from steers born in Year $1(\mathrm{n}=$ 282) were used to develop prediction equations using stepwise regression. Final models using live animal variables included live weight (FWT), UFAT, ULMA, and URPFAT for KGRPRD $\left(\mathrm{R}^{2}=0.83\right)$ and UFAT, URPFAT, ULMA, FWT, and UBDWALL for PRPRD $\left(\mathrm{R}^{2}\right.$
\end{abstract}

$=0.67$ ). Equations developed from USDA yield grade variables resulted in $R^{2}$ values of 0.87 and 0.68 for KGRPRD and PRPRD, respectively. When these equations were applied to steers born in Year $2(\mathrm{n}=252)$, correlations between values predicted from live animal models and actual carcass values were 0.92 for KGRPRD, and ranged from 0.73 to 0.76 for PRPRD. Similar correlations were found for equations developed from carcass measures $(\mathrm{r}=0.94$ for KGRPRD and 0.81 for PRPRD). Both live animal and carcass equations overestimated $(P<0.01)$ actual KGRPRD and PRPRD. Regression of actual values on predicted values revealed a similar fit for equations developed from live animal and carcass measures. Results indicate that composition prediction equations developed from live animal and ultrasound measurements can be useful to estimate carcass composition.

Key Words: Accuracy, Beef, Carcasses, Meat Yield, Prediction, Ultrasound

(C)2003 American Society of Animal Science. All rights reserved.

J. Anim. Sci. 2003. 81:466-473

\section{Introduction}

The use of real-time ultrasound to predict carcass traits in live beef cattle has been evaluated by several workers, and found to be an accurate predictor of carcass 12 th-rib fat thickness and longissimus area (Robinson et al., 1992; Duello, 1993; Herring et al., 1994a). Due to this relationship, equations using a combination of ultrasound and live animal measures have been developed to predict beef carcass composition and have shown the potential to be as accurate as models developed from carcass measurements (Herring et al., 1994b; Williams et al., 1997). In addition, measurements such as rump fat thickness that are made possible with ultrasound and are difficult to obtain on the

\footnotetext{
${ }^{1}$ Correspondence and present address: Dept. of Animal and Poultry Sciences, Virginia Tech, 366 Litton-Reaves Hall, Blacksburg 24061 (phone: 540-231-9159; fax: 540-231-3713; E-mail: sgreiner@vt.edu). Received June 11, 2002.

Accepted November 15, 2002.
}

carcass may enhance the capability of live animal prediction equations (Wallace et al., 1977; Miller et al., 1988; Williams et al., 1997).

However, recent published reports on the validation of live animal prediction equations are rare due to the expense of carcass fabrication. Faulkner et al. (1990) developed equations for cow composition and reported the efficacy of live measurements to be similar to that of carcass measurements when applied to an independent set of animals. Herring et al. (1994b) reported models using live animal traits ranked animals as well as carcass equations, and the USDA cutability equation for retail yield. For live animal prediction equations to be widely used by the beef industry to enhance beef improvement programs or evaluate slaughter cattle, the utility of live animal equations for predicting carcass composition must be investigated. Therefore, the objective of this study was to develop prediction equations for weight and percentage of retail product from live animal and carcass measurements and to validate these equations when applied to another data set. 


\section{Materials and Methods}

This study was conducted in cooperation with the Roman L. Hruska U.S. Meat Animal Research Center (MARC), Clay Center, NE. Five hundred thirty-four calf-fed steers from the 1993 (Year $1, \mathrm{n}=282$ ) and 1994 (Year 2, $\mathrm{n}=252$ ) calf crops of Cycle $\mathrm{V}$ of the Germplasm Evaluation (GPE) program were used (Wheeler et al., 2001). Cycle $\mathrm{V} \mathrm{F}_{1}$ calves were produced by mating Hereford, Angus, and MARC III ( $1 / 4$ Red Poll, $1 / 4$ Hereford, $1 / 4$ Pinzgauer, $1 / 4$ Angus) dams to Hereford, Angus, Tuli, Boran, Belgian Blue, and Brahman bulls. Wheeler et al. (2001) has a detailed description of the sources of the experimental animals and their management, harvest, and processing.

Each year, within $5 \mathrm{~d}$ prior to slaughter, steers were measured ultrasonically by the same Beef Improvement Federation (BIF, 1997)-certified technician for fat thickness between the 12 th and 13 th ribs, $3 / 4$ the length ventrally over the longissimus muscle (UFAT), and for longissimus muscle area between the 12th and 13 th ribs (ULMA). Images were also collected for rump fat thickness at the junction of the biceps femoris and gluteus medius between the the ischium and illium, and parallel to the vertebral column (URPFAT), and for body wall thickness between the 12th and 13th ribs $4 \mathrm{~cm}$ ventral to the longissimus, perpendicular to the external body surface (UBDWALL). Images were taken with an Aloka 500V real-time ultrasound machine (Corometrics Medical Systems, Wallingford, CT) equipped with a $17.2-\mathrm{cm}, 3.5-\mathrm{MHz}$ linear transducer. To ensure proper contact between the ultrasound transducer and animal, the transducer was fitted with a Superflab (Mick Radio-Nuclear Instruments, Inc., Bronx, NY) guide for UFAT and ULMA image collection. In the area to be scanned, hair was clipped, thoroughly curried, and cleaned prior to image collection. Vegetable oil was used as a couplant to obtain adequate acoustic contact. Once a suitable image had been obtained, the image was digitized and stored on a personal computer with a video frame grabber. Only one image per animal was stored for each ultrasound trait. Images were interpreted using software developed at Iowa State University. A final live weight (FWT) was also obtained.

The right side of each carcass was transported to MARC for fabrication into boneless, totally trimmed retail product. Sides were cut into wholesale and subprimal cuts were trimmed to $0 \mathrm{~cm}$ of fat, lean trim, fat trim, and bone as described by Wheeler et al. (1997). Chemical fat content was used to adjust the lean trim to $20 \%$ fat. Weights of boneless, totally trimmed retail cuts and $20 \%$ fat lean trim were summed to give retail product weight (KGRPRD). The percentage of retail product (PRPRD) was calculated by dividing retail product weight by the sum of the parts (retail product weight + fat trim weight + bone weight $) \times 100$. The sum of parts was used rather than HCWT to avoid bias in yield due to the variable amount of shrink that occurred over the 2-wk period required to complete dissection of all sides.

Statistical analyses were conducted using SAS (SAS Inst. Inc., Cary, NC). The data were split by year, with data from Year 1 used to develop linear multiple regression models to predict percentage and weight of retail product. Prediction equations were developed by stepwise regression procedures using either live animal or carcass traits as independent variables. Measurements of adjusted fat thickness (ACFAT), longissimus area (CLMA), estimated percentage of kidney, pelvic, and heart fat (CKPH), hot carcass weight (HCW), and marbling score (MARB) were used to develop carcass prediction equations. Independent variables had to be significant $(P<0.10)$ to remain in models. Equations were evaluated with respect to coefficient of determination $\left(\mathrm{R}^{2}\right)$, root mean square error (RMSE), and Cp as described by Mallow (1973). For models with a close fit, $\mathrm{Cp}$ approaches the number of predictor variables (MacNeil, 1983). Genetic and environmental effects were not considered in the modeling process.

Data from Year 2 were used to validate and test the accuracy of the prediction equations developed. All equations were tested on every animal in the validation data set. The statistics evaluated to compare the validation results from the different prediction equations included the validation RMSE, $\mathrm{R}^{2}$, and the intercept and slope of the regression between the actual and predicted values for retail yield of steers in the validation data set. Correlation coefficients between predicted and actual values were also computed. Bias and absolute residuals were calculated for each prediction equation.

\section{Results and Discussion}

Descriptions of the acronyms assigned to variables are presented in Table 1 . The variation in carcass and live animal traits reflects the diversity of the sire breeds used in Cycle V of the GPE study (Tables 2 and 3). For model development, the PRPRD mean was $65.2 \%$, and the KGRPRD mean was $102.6 \mathrm{~kg}$. Mean PRPRD (63.1\%) was lower and KGRPRD (104.5 kg) was higher for steers used in model validation. Since data for this study were not available for the first slaughter group of the 1994 calf crop (validation set), means for fat measurements, weight, and longissimus area were higher for the model validation than the development set. However, variation in live animal and carcass traits, as well as trait ranges, was similar for the model development and validation sets. The relationships between ultrasound and carcass measurements for this study have been reported in Greiner et al. (2003).

Regression equations for predicting PRPRD and KGRPRD from live animal measurements are presented in Table 4 . The majority of the variation in PRPRD was explained by UFAT, with an $\mathrm{R}^{2}$ value of 
Table 1. Description of acronyms

\begin{tabular}{|c|c|}
\hline Acronym & Definition \\
\hline FWT & Final unshrunk weight, kg \\
\hline UFAT & Ultrasound 12th-rib fat thickness, cm \\
\hline ULMA & Ultrasound longissimus muscle area, $\mathrm{cm}^{2}$ \\
\hline URPFAT & Ultrasound rump fat thickness, $\mathrm{cm}$ \\
\hline UBDWALL & Ultrasound body wall thickness, $\mathrm{cm}$ \\
\hline $\mathrm{HCW}$ & Hot carcass weight, $\mathrm{kg}$ \\
\hline ACFAT & Adjusted carcass 12 th-rib fat thickness, $\mathrm{cm}$ \\
\hline CLMA & Carcass longissimus muscle area, $\mathrm{cm}^{2}$ \\
\hline $\mathrm{CKPH}$ & Estimated kidney, pelvic, and heart fat, $\%$ \\
\hline MARB & $\begin{array}{c}\text { Marbling score, } 300=\text { traces }^{0}, 400=\text { slight }^{0}, 500=\text { small }^{0} \\
600=\text { modest }^{0}, 700=\text { moderate }^{0}\end{array}$ \\
\hline KGRPRD & $\begin{array}{c}\text { Weight of totally trimmed, boneless retail product and lean trim } \\
\text { adjusted to } 20 \% \text { fat from one carcass side, } \mathrm{kg}\end{array}$ \\
\hline PRPRD & $\begin{array}{l}\text { Totally trimmed, boneless retail product and lean trim } \\
\text { adjusted to } 20 \% \text { fat expressed as a percentage of cold carcass side weight }\end{array}$ \\
\hline
\end{tabular}

0.59 when fit alone. In addition to UFAT, URPFAT measurements have been shown to be valuable live animal predictors of retail yield (Williams et al., 1997; Miller et al., 1988). In the present study, URPFAT was the second variable to enter into the model using stepwise regression $\left(R^{2}=0.44\right.$ alone), and together UFAT and URPFAT accounted for $63 \%$ of the variation in PRPRD (data not shown). Of interest was the inclusion of an additional ultrasonic fat measurement, UBDWALL, which is related to percentage and weight of retail product when measured on the carcass (Brungardt and Bray, 1963; Cross et al., 1973). Although UBDWALL had a strong relationship with PRPRD ( $\mathrm{r}$ $=-0.49$ ), it was the last variable to be included in prediction equations for PRPRD developed from stepwise regression (Eq. 3).

Final live weight accounted for the majority of the variation in KGRPRD ( $R^{2}=0.63$ alone), and combined with UFAT explained $77 \%$ of the variability in weight of retail product (data not shown). Inclusion of ULMA (Eq. 4) increased the $\mathrm{R}^{2}$ value by 0.05 , and reduced RMSE by $0.79 \mathrm{~kg}$. The final model for prediction of KGRPRD using live animal variables included FWT, UFAT, ULMA, and URPFAT (Eq. 5).

The best live animal equations for PRPRD and KGRPRD (Eq. 3 and 5) were similar in their predictive power $\left(\mathrm{R}^{2}\right)$ to yield grade trait-based carcass equations (Eq. 6 and 8; Table 5). Researchers have also reported marbling score to be a useful predictor of carcass composition (Kauffman et al., 1973; Crouse and Dikeman, 1976). In the present study, MARB explained an additional $4 \%$ of the variation in PRPRD when included with yield grade variables (Eq. 6 vs. 7), and it was a significant variable for KGRPRD prediction (Eq. 9).

All equations overestimated $(P<0.01)$ actual PRPRD. Means for bias and absolute residual between

Table 2. Simple statistics for live animal and carcass traits used in model development (Year 1) ${ }^{\mathrm{a}}$

\begin{tabular}{lcccc}
\hline \hline Trait & Mean & SD & Minimum & Maximum \\
\hline Live & & & & \\
FWT, kg & 547.9 & 63.7 & 354.3 & 731.3 \\
UFAT, cm & 1.00 & 0.35 & 0.23 & 2.01 \\
ULMA, cm ${ }^{2}$ & 77.0 & 7.5 & 59.3 & 102.2 \\
URPFAT, cm & 1.04 & 0.32 & 0.36 & 2.29 \\
UBDWALL, cm & 5.21 & 0.75 & 3.34 & 7.46 \\
Carcass & & & & \\
HCW, kg & 333.6 & 40.4 & 214.4 & 2.79 \\
Actual fat thickness, cm & 1.04 & 0.41 & 0.25 & 2.54 \\
ACFAT, cm & 0.98 & 0.41 & 0.25 & 100.0 \\
CLMA, cm & & 8.0 & 58.7 & 4.50 \\
CKPH, \% & 76.0 & 0.60 & 1.00 & 5.46 \\
USDA yield grade & 2.78 & 0.71 & 1.25 & 690.0 \\
MARB & 3.04 & 63.5 & 350.0 & 212.6 \\
Side wt, kg & 501.2 & 19.0 & 103.1 & 138.2 \\
KGRPRD, kg & 157.7 & 12.8 & 72.2 & 75.8 \\
PRPRD, \% & 102.6 & 4.3 & 55.0 & \\
\hline
\end{tabular}

asee Table 1 for a description of acronyms.

${ }^{\mathrm{b}} \mathrm{Sum}$ of retail product, fat trim, and bone. 
Table 3. Simple statistics for live animal and carcass traits used in model validation (Year 2) ${ }^{\mathrm{a}}$

\begin{tabular}{lcccc}
\hline \hline Trait & Mean & SD & Minimum & Maximum \\
\hline Live & & & & \\
FWT, kg & 563.0 & 62.7 & 397.9 & 760.8 \\
UFAT, cm & 1.05 & 0.35 & 0.41 & 2.06 \\
ULMA, cm ${ }^{2}$ & 80.8 & 7.3 & 62.5 & 104.0 \\
URPFAT, cm & 1.15 & 0.32 & 0.30 & 2.06 \\
UBDWALL, cm & 5.53 & 0.86 & 3.56 & 8.43 \\
Carcass & & & & \\
HCW, kg & 352.4 & 41.4 & 247.1 & 462.9 \\
Actual fat thickness, cm & 1.14 & 0.46 & 0.25 & 2.54 \\
ACFAT, cm & 1.05 & 0.44 & 0.25 & 2.29 \\
CLMA, cm & & 8.8 & 43.2 & 11.6 \\
CKPH, \% & 80.5 & 0.55 & 1.50 & 5.00 \\
USDA yield grade & 3.17 & 0.75 & 1.37 & 770.0 \\
MARB & 3.12 & 60.4 & 390.0 & 220.5 \\
Side wt, kg & 506.9 & 20.0 & 118.9 & 144.1 \\
KGRPRD, kg & 165.8 & 12.9 & 75.8 & 74.7 \\
PRPRD, \% & 104.5 & 3.9 & 53.7 & \\
\hline
\end{tabular}

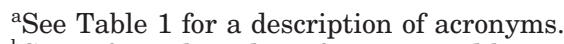

${ }^{\mathrm{b}} \mathrm{Sum}$ of retail product, fat trim, and bone.

Equations 3 and 6 and between Equations 3 and 7 were not different $(P>0.10)$, suggesting that the best live animal model (Eq. 3) was as accurate as carcass variable models (Eq. 6 and 7) for estimating PRPRD. Correlation coefficients between actual and predicted values of PRPRD ranged from 0.73 to 0.76 for live animal equations and were 0.80 and 0.81 for carcass equations. As a comparison, the correlation between YG and PRPRD for the validation set was -0.79 (data not shown).

Reports that deal concurrently with model development and validation are limited. The USDA cutability equation derived from the regression equation by Murphy et al. (1960) has been the most widely tested on independent populations of beef carcasses. Generally, the USDA equation has been an acceptable predictor of actual yields, with correlation coefficients ranging from 0.73 to 0.85 (Brackelsberg and Willham, 1968; Cross et al., 1973; Crouse et al., 1975). Although carcass fabrication procedures are different, correlation coefficients in the present study between actual and predicted retail yield using live animal equations $(\mathrm{r}=$ 0.73 to 0.76 ) are similar to those generally reported for the USDA equation.

As with PRPRD, both live animal and carcass equations overestimated actual KGRPRD $(P<0.01$; Table 6 ). Mean bias for live animal Equation 5 was lower $(P$ $<0.01$ ) than for carcass Equations 8 and 9. Absolute residual means between the best live animal (Eq. 5) and carcass (Eq. 8 and 9) equations were not different $(P>0.10)$, suggesting that the average amount of error introduced by live animal and carcass prediction equations was similar. Additionally, correlation coefficients between actual and predicted KGRPRD ranged from 0.92 to 0.94 and were similar for equations derived from either live animal or carcass variables.

Herring et al. (1994b) compared rank correlations between predicted values for PRPRD and KGRPRD using equations developed from live animal and ultrasound traits, carcass traits, and the USDA cutability equation. Models using live animal traits ranked the animals as well as carcass models and the USDA equa-

Table 4. Prediction equations for weight and percentage of retail product developed from live animal measurements ${ }^{\mathrm{a}}$

\begin{tabular}{|c|c|c|c|c|c|c|c|c|c|}
\hline \multirow[b]{2}{*}{$\begin{array}{l}\text { Dependent variable } \\
\text { and equation }\end{array}$} & \multirow[b]{2}{*}{$\mathrm{R}^{2}$} & \multirow[b]{2}{*}{ RMSE } & \multirow[b]{2}{*}{$\mathrm{Cp}$} & \multicolumn{6}{|c|}{ Partial regression coefficients } \\
\hline & & & & Intercept & $\begin{array}{l}\text { UFAT, } \\
\mathrm{cm}\end{array}$ & $\begin{array}{l}\text { URPFAT, } \\
\mathrm{cm}\end{array}$ & $\begin{array}{l}\text { ULMA, } \\
\mathrm{cm}^{2}\end{array}$ & $\begin{array}{l}\text { FWT, } \\
\text { kg }\end{array}$ & $\begin{array}{c}\text { UBDWALL, } \\
\mathrm{kg}\end{array}$ \\
\hline \multicolumn{10}{|l|}{ PRPRD } \\
\hline 1 & 0.64 & 2.60 & 25.50 & 69.32 & -8.502 & - & 0.135 & -0.011 & - \\
\hline 2 & 0.66 & 2.53 & 8.88 & 69.69 & -6.93 & -2.936 & 0.121 & -0.007 & - \\
\hline 3 & 0.67 & 2.51 & 6.00 & 70.83 & -6.033 & -2.913 & 0.138 & -0.008 & -0.598 \\
\hline \multicolumn{10}{|l|}{ KGRPRD } \\
\hline 4 & 0.82 & 5.42 & 14.88 & -6.05 & -11.430 & - & 0.461 & 0.154 & - \\
\hline 5 & 0.83 & 5.30 & 4.00 & -5.39 & -8.597 & -5.170 & 0.437 & 0.161 & - \\
\hline
\end{tabular}

asee Table 1 for a description of acronyms. RMSE = root mean square error. 
Table 5. Prediction equations for weight and percentage of retail product developed from carcass measurements ${ }^{\mathrm{a}}$

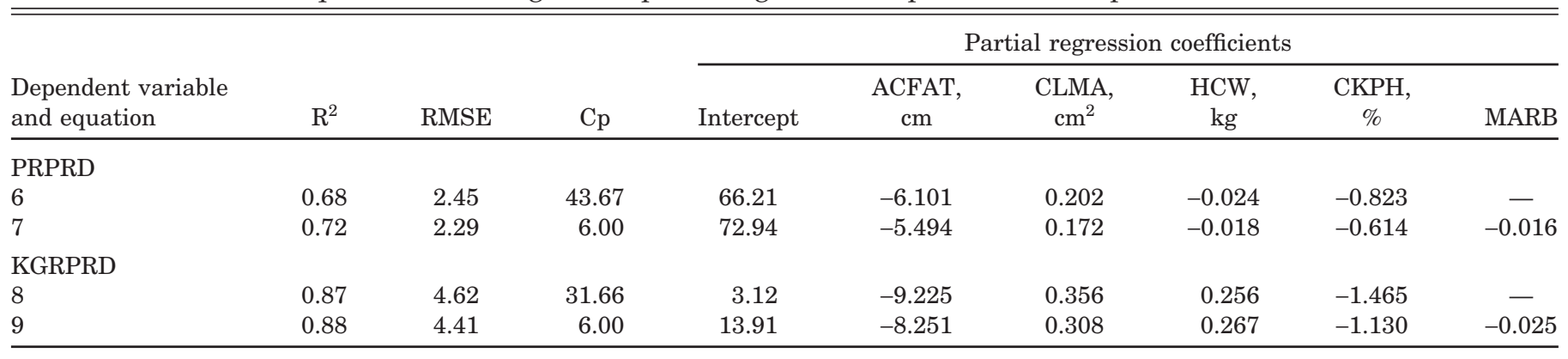

${ }^{\text {a See Tables }} 1$ and 4 for a description of acronyms.

tion for retail yield, whereas live animal and carcass equations ranked animals equally for weight of retail product. Correlations for this study reported in Table 6 follow a similar trend.

Analysis of the regression of predicted values on observed values for PRPRD and KGRPRD are given in Tables 7. An unbiased prediction model should result in an intercept not different from zero and a slope not different from one (MacNeil, 1983). In the present study, as more variables were included in live animal or carcass equations, a greater degree of fit was exhibited as intercept and slope values more closely approached zero and one, respectively. Equation 3 exhibited the greatest degree of fit for live animal models, and accounted for 57\% of the actual variation in PRPRD. In comparison, the best carcass equation (Eq. 7) accounted for $66 \%$ of the variation in actual PRPRD.

Carcass equations for KGRPRD (Eq. 8 and 9) exhibited intercepts that were not different from zero $(P>$ 0.10 ) and slopes that were very close to one, indicating a good model fit. Live animal equations accounted for $84 \%$ of the variation in actual KGRPRD, whereas carcass equations accounted for $88 \%$ (Table 7). Carcass weight and live weight have been shown to be the best single predictors of retail product weight for carcass and live animal equations, respectively (Epley et al., 1970; Williams et al., 1997). Therefore, some of the differences noted between live animal and carcass equations for KGRPRD may be due to animal variation in dressing percentage.

Faulkner et al. (1990) developed prediction equations for various cow composition traits using live animal and carcass variables. When tested on an independent set of animals, live animal equations (including live weight, 12th-rib ultrasound fat, and hip height) for percentage of fat and weight of fat-free lean exhibited the greatest degree of fit when observed carcass values were regressed on predicted values. In agreement with the results reported in Table 7, Faulkner et al. (1990) found $R^{2}$ values were similar for live and carcass estimates of composition.

Residual distributions are more appropriate indicators of model fit than correlations between predicted and actual values, as correlations do not account for bias. Cumulative frequency analysis for Equation 3, which includes all live animal measurements, indicated $34.1 \%$ of the predicted observations had residuals smaller than $\pm 1 \%, 51.6 \%$ smaller than $\pm 2 \%$, and $71.4 \%$ smaller than $\pm 3 \%$. Carcass Equation 6 had 34.9, 56.4 , and $71.0 \%$ of residuals smaller than $\pm 1,2$, and $3 \%$, respectively. For all equations, the largest number of predicted observations had residuals $\pm 0.5 \%$.

Cumulative frequency distributions of the residuals for KGRPRD equations were also evaluated. Live animal Equation 5 had $31.4 \%$ of the observations with residuals smaller than $\pm 2 \mathrm{~kg}, 61.5 \%$ smaller than \pm 4

Table 6. Validation statistics for retail product equations

\begin{tabular}{lcccc}
\hline \hline Equation $^{\mathrm{a}}$ & Predicted value & Bias $^{* *}$ & Absolute residual & $\begin{array}{c}\text { Correlation of actual and } \\
\text { predicted value** }\end{array}$ \\
\hline Live animal & & & & \\
1 & $65.09 \%$ & $1.94 \%$ & $2.65 \%$ & 0.73 \\
2 & $64.87 \%$ & $1.72 \%$ & $2.49 \%$ & 0.75 \\
3 & $64.79 \%$ & $1.63 \%$ & $2.42 \%$ & 0.76 \\
4 & $106.11 \mathrm{~kg}$ & $1.57 \mathrm{~kg}$ & $4.34 \mathrm{~kg}$ & 0.92 \\
5 & $105.73 \mathrm{~kg}$ & $1.19 \mathrm{~kg}$ & $4.28 \mathrm{~kg}$ & 0.92 \\
Carcass & & & & 0.80 \\
6 & $64.88 \%$ & $1.73 \%$ & $2.34 \%$ & 0.81 \\
7 & $64.90 \%$ & $1.75 \%$ & $2.36 \%$ & 0.94 \\
8 & $107.83 \mathrm{~kg}$ & $3.29 \mathrm{~kg}$ & $4.27 \mathrm{~kg}$ & 0.94 \\
9 & $107.87 \mathrm{~kg}$ & $3.33 \mathrm{~kg}$ & $4.27 \mathrm{~kg}$ & \\
\hline
\end{tabular}

asee Tables 4 and 5 for a description of equations.

***Values differ from zero $(P<0.01)$. 
Table 7. Regression of predicted values on actual values for retail product equations

\begin{tabular}{|c|c|c|c|c|}
\hline Equation $^{\mathrm{a}}$ & Intercept & $\mathrm{b}_{1}$ & $\mathrm{R}^{2}$ & RMSE \\
\hline \multicolumn{5}{|c|}{ Live animal } \\
\hline 1 & $8.02 \pm 3.24$ & $0.85 \pm 0.05$ & 0.54 & $2.63 \%$ \\
\hline 2 & $8.17 \pm 3.08$ & $0.85 \pm 0.05$ & 0.56 & $2.56 \%$ \\
\hline 3 & $7.83 \pm 3.03$ & $0.85 \pm 0.05$ & 0.57 & $2.53 \%$ \\
\hline 4 & $-6.50 \pm 3.10$ & $1.05 \pm 0.03$ & 0.84 & $5.18 \mathrm{~kg}$ \\
\hline 5 & $-4.98 \pm 3.03$ & $1.04 \pm 0.03$ & 0.84 & $5.14 \mathrm{~kg}$ \\
\hline \multicolumn{5}{|l|}{ Carcass } \\
\hline 6 & $9.21 \pm 2.55$ & $0.83 \pm 0.04$ & 0.64 & $2.31 \%$ \\
\hline 7 & $8.96 \pm 2.48$ & $0.83 \pm 0.04$ & 0.66 & $2.26 \%$ \\
\hline 8 & $-2.13 \pm 2.50$ & $0.99 \pm 0.02$ & 0.88 & $4.45 \mathrm{~kg}$ \\
\hline 9 & $-2.07 \pm 2.46$ & $0.99 \pm 0.02$ & 0.88 & $4.40 \mathrm{~kg}$ \\
\hline
\end{tabular}

${ }^{\text {aS See Tables }} 4$ and 5 for description of equations. RMSE = root mean square error.

$\mathrm{kg}$, and $79.0 \%$ smaller than $\pm 6 \mathrm{~kg}$. As with PRPRD, KGRPRD residual frequency distributions were similar for live animal and carcass equations. However, carcass Equation 8 had the highest percentage of residuals within $\pm 1,2,3$, and $4 \mathrm{~kg}$.

Predicted values for PRPRD, mean bias, absolute residual means, and correlations between actual and predicted values for PRPRD are reported in Table 8 for animals with low $(<61 \%)$, medium $(61$ to $65 \%)$, and high (>65\%) PRPRD. Results indicate that both live animal and carcass equations overestimated actual PRPRD in the low and medium retail yield categories. Mean bias and absolute residual means were larger in magnitude for the low cutability group as compared to the medium and high retail yield groups. Correlation coefficients between actual and predicted values were also lower in the low retail yield category. Live animal equations underestimated actual PRPRD in the high retail yield category, whereas carcass equations overestimated actual PRPRD. Absolute residual means were lowest in the high retail yield category for both carcass and live animal models. Correlation coefficients between actual and predicted values ranged from 0.55 to 0.57 for the medium retail yield category, and were 0.72 in the high retail yield category for carcass trait equations.

Hedrick and Krause (1975) reported similar trends when actual retail yields of 590 steer carcasses were compared to predicted yields determined by the USDA cutability equation. Predicted retail yields of low-cutability $(<50 \%)$ steer carcasses exceeded actual retail yields by $1.20 \%$, whereas predicted retail yields of high-cutability carcasses (>55\%) were $3.49 \%$ less than actual values.

Retail yield categories were also defined for KGRPRD, and associated statistics are reported in Table 9. Mean bias revealed overestimation for both live animal and carcass equations for steers with less than $98 \mathrm{~kg}$ or from 98 to $111 \mathrm{~kg}$ retail product. Live animal equations underestimated actual value for animals with greater than 111 KGRPRD, whereas carcass equations overestimated in this category. Absolute residual means were similar across retail yield categories for live animal equations, whereas absolute resid-

Table 8. Relationship between actual and predicted percentage of retail product for different categories of retail yield

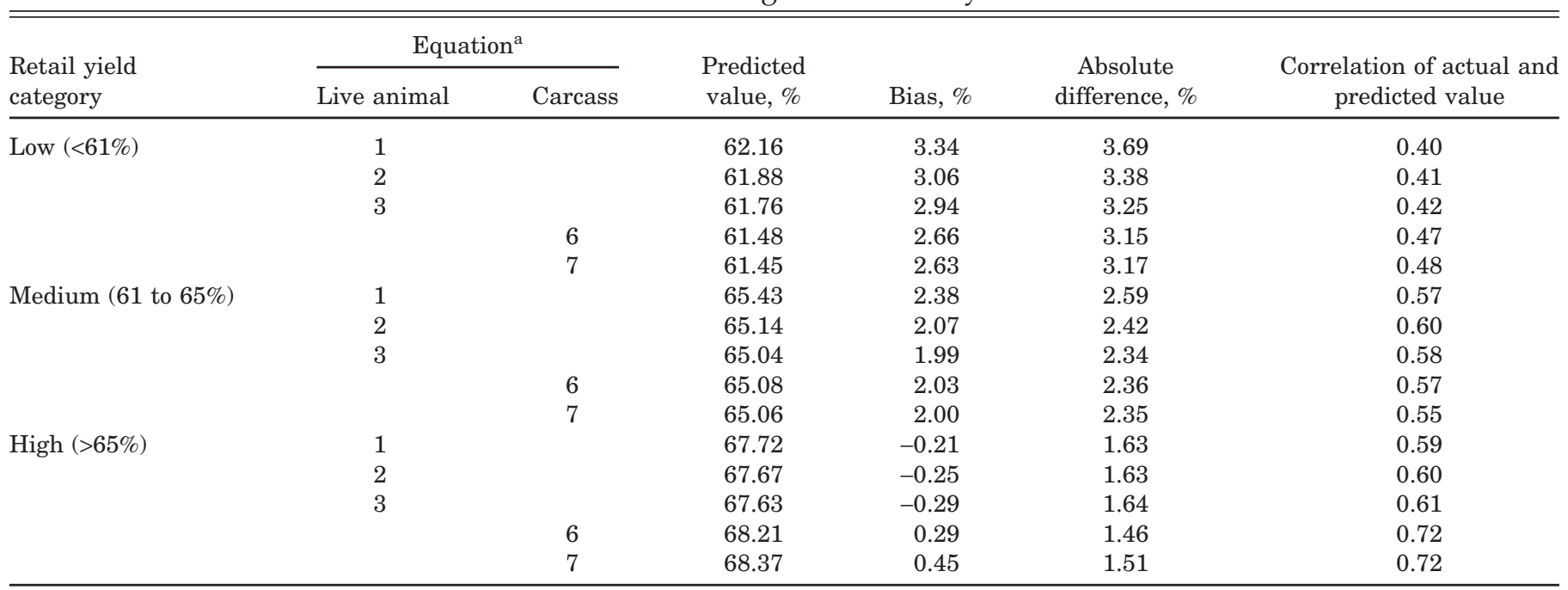

${ }^{\text {aSee Tables }} 4$ and 5 for a description of equations. 
Table 9. Relationship between actual and predicted weight of retail product for different categories of retail yield

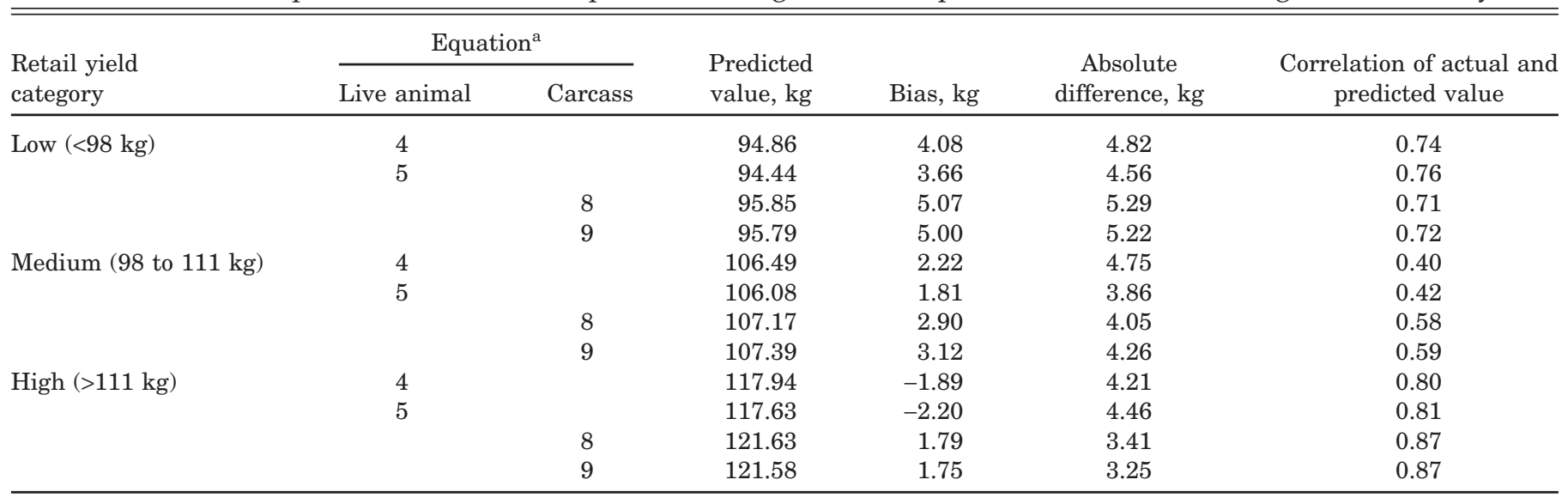

asee Tables 4 and 5 for a description of equations.

ual means tended to decrease with additional KGRPRD for carcass-based models.

The ability of an equation developed from ultrasound and live animal traits to predict percentage or weight of carcass retail product as well as those developed from carcass measures is dependent on the accuracy of the ultrasound measures. Several studies have shown that ultrasound has a tendency to overestimate carcass 12 th-rib fat thickness in leaner cattle and underestimate this same trait in fatter cattle (Duello, 1992; Robinson et al., 1992; Herring et al., 1994a). Since 12th-rib fat is the most important predictor and is inversely related to retail yield (Crouse and Dikeman, 1976; Abraham et al., 1980), measurement bias with ultrasound would likely result in overestimation of retail yield in low-cutability cattle and underestimation of retail yield in high-cutability cattle such as that reported in this study.

Equation 3, which includes UFAT, URPFAT, ULMA, FWT, and UBDWALL appears to be the best live animal model for prediction of PRPRD based upon the various validation statistics. Inclusion of alternative ultrasound fat measurement sites (URPFAT and UBDWALL) improved the accuracy and precision of models compared to traditional live animal measurements of UFAT, ULMA, and FWT (Equation 1).

\section{Implications}

Results from this research indicate that live animal prediction equations developed from ultrasonic measurements are similar in their predictive power and accuracy for weight and percentage of beef carcass retail product to equations developed from carcass measurements. Ultrasonic measurement of rump fat and body wall thickness, two measurements that are easy to obtain on the live animal, added to the predictive capability of traditional ultrasound measures of 12th-rib fat and longissimus muscle area. Application of live animal prediction models that successfully predict carcass composition in slaughter progeny and breeding animals will allow for rapid genetic progress and enable producers to be competitive in a valuebased marketing system.

\section{Literature Cited}

Abraham, H. C., C. E. Murphy, H. R. Cross, G. C. Smith, and W. J. Franks Jr. 1980. Factors affecting beef carcass cutability: An evaluation of the USDA yield grades for beef. J. Anim. Sci. 50:841-851.

BIF. 1997. Proc. 29th Annu. Mtg. of the Beef Improv. Fed., Dickinson, ND.

Brackelsberg, P. O., and R. L. Willham. 1968. Relationships among some common live and carcass measurements and beef carcass composition. J. Anim. Sci. 27:53-57.

Brungardt, V. H., and R. W. Bray. 1963. Estimate of retail yield of the four major cuts in the beef carcass. J. Anim. Sci. 22:177-182.

Cross, H. R., Z. L. Carpenter, and G. C. Smith. 1973. Equations for estimating boneless retail cut yields from beef carcasses. J. Anim. Sci. 37:1267-1272.

Crouse, J. D., and M. E. Dikeman. 1976. Determinates of retail product of carcass beef. J. Anim. Sci. 42:584-591.

Crouse, J. D., M. E. Dikeman, R. M. Koch, and C. E. Murphy. 1975. Evaluation of traits in the U.S.D.A. yield grade equation for predicting beef carcass cutability in breed groups differing in growth and fattening characteristics. J. Anim. Sci. 41:548-553.

Duello, D. A. 1993. The use of real-time ultrasound measurements to predict composition and estimate genetic parameters of carcass traits in live beef cattle. Ph.D. Thesis, Iowa State Univ., Ames.

Epley, R. J., H. B. Hedrick, W. C. Stringer, and D. P. Hutcheson. 1970. Prediction of weight and percent retail cuts of beef using five carcass measurements. J. Anim. Sci. 30:872-879.

Faulkner, D. B., D. F. Parrett, F. K. McKeith, and L. L. Berger. 1990. Prediction of fat cover and carcass composition from live and carcass measurements. J. Anim. Sci. 68:604-610.

Greiner, S. P., G. H. Rouse, D. E. Wilson, L. V. Cundiff, and T. L. Wheeler. 2003. The relationship between real-time ultrasound measurements and carcass fat thickness and longissimus muscle area in beef cattle. J. Anim. Sci. (In press).

Hedrick, H. B., and G. F. Krause. 1975. Comparisons of predicted and actual retail yields from steer and heifer carcasses and equations for estimating retail yields. J. Anim. Sci. 41:508-512.

Herring, W. O., D. C. Miller, J. K. Bertrand, and L. L. Benyshek. 1994a. Evaluation of machine, technician, and interpreter effects on ultrasonic measures of backfat and longissimus muscle area in beef cattle. J. Anim. Sci. 72:2216-2226.

Herring, W. O., S. E. Williams, J. K. Bertrand, L. L. Benyshek, and D. C. Miller. 1994b. Comparison of live and carcass equations 
predicting percentage of cutability, retail product weight, and trimmable fat in beef cattle. J. Anim. Sci. 72:1107-1118.

Kauffman, R. G., M. E. Van Ess, R. A. Long, and D. M. Schaefer. 1975. Marbling: Its use in predicting beef carcass composition. J. Anim. Sci. 40:235-241.

MacNeil, M. D. 1983. Choice of a prediction equation and the use of the selected equation in subsequent experimentation. J. Anim. Sci. 57:1328-1336.

Mallows, C. L. 1973. Some comments on Cp. Technometrics 15:661.

Miller, M. F., H. R. Cross, J. F. Baker, and F. M. Byers. 1988. Evaluation of live and carcass techniques for predicting beef carcass composition. Meat Sci. 23:111-129.

Murphy, C. E., D. K. Hallett, W. E. Tyler, and J. C. Pierce Jr. 1960. Estimating yields of retail cuts from beef carcasses. J. Anim. Sci. 19:1240 (Abstr.).

Robinson, D. L., C. A. McDonald, K. Hammond, and J. W. Turner. 1992. Live animal measurement of carcass traits by ultrasound:
Assessment and accuracy of sonographers. J. Anim. Sci. 70:1667-1676.

Wallace, M. A., J. R. Stouffer, and R. G. Westervelt. 1977. Relationships of ultrasonic and carcass measurements with retail yield in beef cattle. Livest. Prod. Sci. 4:153-164.

Wheeler, T. L., L. V. Cundiff, R. M. Koch, M. E. Dikeman, and J. D. Crouse. 1997. Characterization of biological types of steers (Cycle IV): Wholesale, subprimal, and retail product yields. J. Anim. Sci. 75:2389-2403.

Wheeler, T. L., L. V. Cundiff, S. D. Shackelford and M. Koohmaraie. 2001. Characterization of biological types of cattle (Cycle V): Carcass traits and longissimus palatability. J. Anim. Sci. 79:1209-1222.

Williams, R. E., J. K. Bertrand, S. E. Williams, and L. L. Benyshek. 1997. Biceps femoris and rump fat as additional ultrasound measurements for predicting retail product and trimmable fat in beef carcasses. J. Anim. Sci. 75:7-13. 